\title{
ASSESSMENT OF ANTHROPOMETRIC PARAMETERS IN ADOLESCENT AND YOUNG PEOPLE
}

\author{
Nikita Mathur', Varun Malhotra², Usha Dhar³, Yogesh Tripathi', Shivani Gupta ${ }^{5}$ \\ ${ }_{1}^{1}$ Postgraduate Student, Santosh Medical College. \\ 2 Professor and HOD, Department of Physiology, Santosh Medical College. \\ ${ }^{3}$ Ex-Professor and HOD, Department of Physiology, Santosh Medical College. \\ ${ }^{4}$ Professor and Dean, Santosh Medical College. \\ 5Undergraduate Student, Santosh Medical College.
}

\section{ABSTRACT}

\section{BACKGROUND AND OBJECTIVES}

Obesity is becoming a pandemic these days. People are overweight and are losing the joy of self-control. Lack of exercise, poor dietary habits lead to hypertension and diabetes mellitus. It is essential to make students aware of their faulty habits so they may correct it at an early age.

\section{MATERIAL AND METHODS}

We analysed the height, weight, blood pressure, BMI for the students.

\section{RESULTS}

BMI is statistically correlated with BP.

\section{CONCLUSION}

It is important to undertake prevention and control programs to make young people aware of harmful effects of sedentary lifestyles, benefits and usefulness of maintaining a healthy BMI, to undertake measures of reducing weight and fat by regular exercise, proper dieting and stopping smoking and alcohol intake for which young people need to be counselled.

\section{KEYWORDS}

Obesity, Overweight, Hypertension, BMI, Exercise.

HOW TO CITE THIS ARTICLE: Mathur N, Malhotra V, Dhar U, et al. Assessment of anthropometric parameters in adolescent and young people. J. Evolution Med. Dent. Sci. 2016;5(69):4976-4979, DOI: 10.14260/jemds/2016/1130

\section{INTRODUCTION}

During the past few decades, a great deal of attention has been focused on the relationship between body fat, hypertension and physical activity. Excessive body fat and hypertension are important public health challenges in both economically developing and developed countries. ${ }^{1}$ Many healthy or unhealthy lifelong habits begin in adolescent period and have lifelong impact on the lifestyle diseases. ${ }^{2}$ Today, the problem has started appearing in developing countries. Overweight and obesity represent a rapidly growing threat to the healthy population in an increasing number of countries. ${ }^{3}$ Overweight and obesity may account for as many as $15-30 \%$ of deaths from Coronary Heart Disease and $65-75 \%$ of new cases of diabetes mellitus. $^{4}$ A variety of adaptations in cardiorespiratory structure and function can occur in the individuals as adipose tissue accumulates in excess amount even in the absence of comorbidities. ${ }^{5}$ It is now recognised that the hypertension in children is not as uncommon as previously believed and in most cases represents early onset of essential rather than secondary hypertension. ${ }^{6-7}$ The high prevalence rates of noncommunicable diseases, particularly of hypertension in developing countries is gaining much attention. ${ }^{8}$ Blood pressure and hypertension prevalence rates were much higher in men than in women demonstrating gender dichotomy in blood pressure with high pressure seen in men. ${ }^{9}$

Financial or Other, Competing Interest: None.

Submission 22-07-2016, Peer Review 17-08-2016,

Acceptance 22-08-2016, Published 27-08-2016.

Corresponding Author:

Varun Malhotra,

J-117/25, Noida-201301.

E-mail: malhotravarundr@gmail.com

DOI: $10.14260 /$ jemds/2016/1130
Normal levels of both systolic and diastolic blood pressure are particularly efficient function of vital organs such as the heart, brain and kidneys and for the overall health and wellbeing. ${ }^{8}$ Control of hypertension varies in different studies from different countries and it certainly places an excessive financial burden on population and health systems consuming scarce resources. ${ }^{10}$

This study was conducted to determine weight and height for calculating BMI and to determine blood pressure of adolescent and young people.

\section{MATERIAL AND METHODS}

The present study was conducted among all the medical, dental and nursing students of Santosh Medical College and Hospital, Ghaziabad. The aim of the study was to find out correlation if any in between normal weight, over weight and underweight with BP in adolescents and young people studying in Santosh University.

\section{Height}

It was measured [to the nearest $0.5 \mathrm{~cm}$ ] with the subject standing in an erect position using a non-elastic measuring tape fastened to a vertical wall. The patient was asked to stand upright, barefoot on the ground with heels, buttocks, upper back and back of head making firm contact with the wall.

\section{Weight}

It was recorded using standard bathroom weighing scale. The subject was asked to stand motionless on weighing scale and measured to the same degree of accuracy, i.e. nearest to $0.5 \mathrm{~kg}$.

\section{BMI}

It refers to Body Mass Index. It was calculated using internationally accepted formula; 
BMI = Weight [in $\mathrm{kg}] /$ Height $\left[\mathrm{in} \mathrm{m}^{2}\right]$, i.e. $\mathrm{kg} / \mathrm{m}^{2}$

All instruments and equipment were calibrated each morning to the instructions. According to the international standard.

BMI is Classified as follows

Normal: 18.5-24.9.

Overweight: $25-29.9$.

Obese: $>30$.

\section{Blood Pressure}

It was measured on right arm by auscultatory method using mercury sphygmomanometer of a reputed brand and appropriate size cuff. The subject was made to sit comfortably with his/her back supported, feet on the floor and right arm supported with cubital fossa at heart level.

Hypertension: Systolic BP $\geq 140 \mathrm{mmHg}$.

Diastolic BP $\geq 90 \mathrm{mmHg}$.

Norm Tension: Systolic BP $\leq 140 \mathrm{mmHg}$.

Diastolic BP $\leq 90 \mathrm{mmHg}$.

\section{OBSERVATIONS AND RESULTS}

A total of 308 students were included in the study consisting of 131 males (43\%) and 177 females (57\%).

The parameters height, weight and BP were correlated using SPSS software version 11.5. The regression/correlation coefficient was reported. In addition, the normal, overweight and obese group of subjects was statistically compared using paired t-test using SPSS software version 11.5. The above three groups were matched in terms of age, sex, food habits, education and socio-economic status.

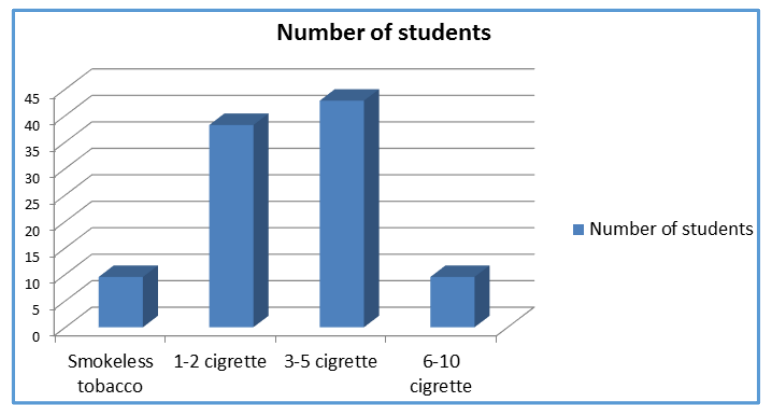

Fig. 1: Distribution of Students who Smoke Per Number of Students

\section{Students consuming tobacco}

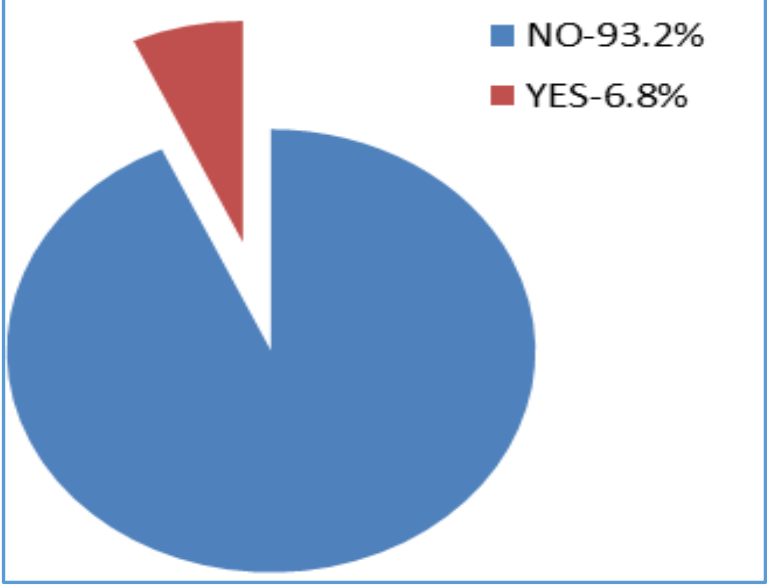

Fig. 2: Distribution of Students According to Tobacco Consumption

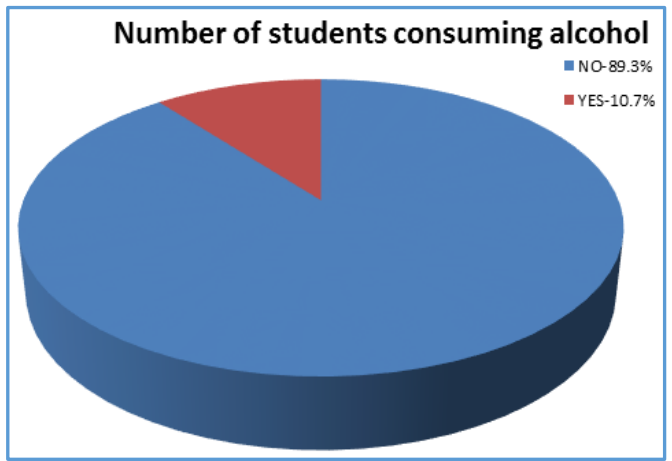

Fig. 3: Distribution of Students who Consume Alcohol

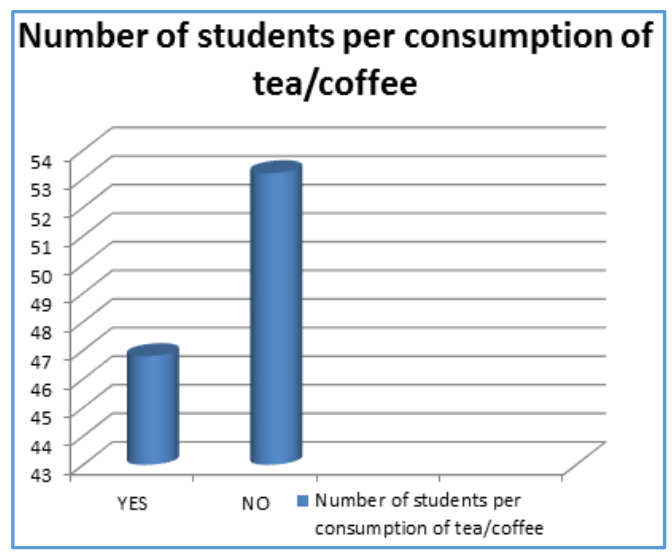

Fig. 4: Distribution of Students Per Consumption of Tea/Coffee

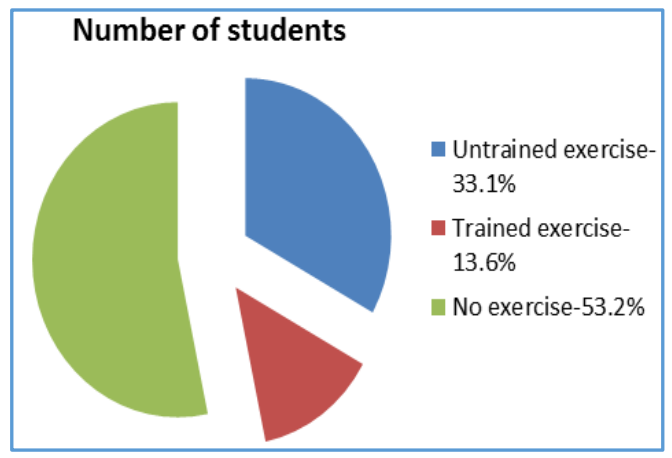

Fig. 5: Distribution of Students Per History of Exercises

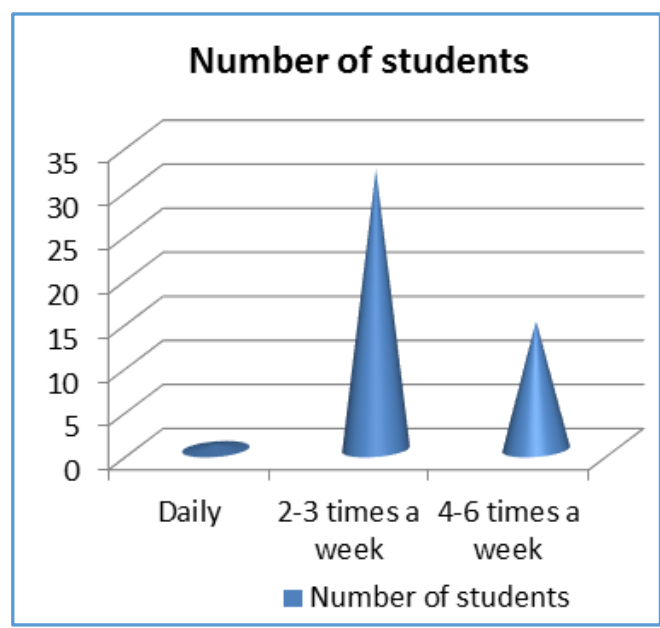

Fig. 6: Distribution of Students Per Frequency of Exercises 


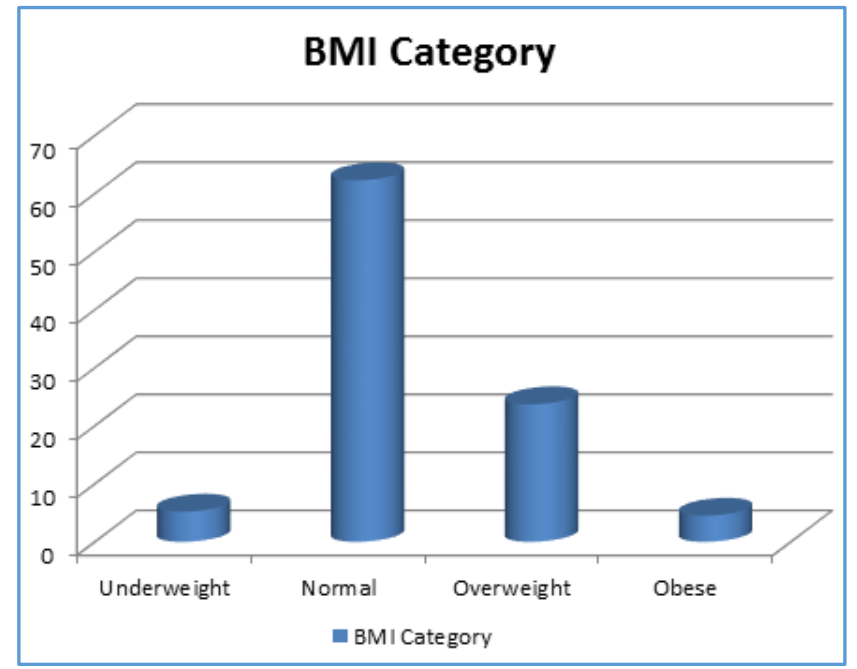

Fig. 7: Distribution of Students According to their BMI

\begin{tabular}{|c|c|c|c|c|c|}
\hline & & \multicolumn{3}{|c|}{ BMI } & \multirow[t]{2}{*}{ Total } \\
\hline & & Normal & \begin{tabular}{|c|} 
Over \\
Weight
\end{tabular} & Obese & \\
\hline \multirow[b]{2}{*}{$\begin{array}{c}\text { Normal } \\
\text { BP }\end{array}$} & Count & 174 & 40 & 9 & 223 \\
\hline & $\begin{array}{c}\% \\
\text { within } \\
\text { BMI }\end{array}$ & $83.70 \%$ & $54.80 \%$ & $33.30 \%$ & $72.40 \%$ \\
\hline \multirow[b]{2}{*}{$\begin{array}{l}\text { Hyper } \\
\text { tension }\end{array}$} & Count & 7 & 31 & 18 & 56 \\
\hline & $\begin{array}{c}\% \\
\text { within } \\
\text { BMI }\end{array}$ & $3.40 \%$ & $42.50 \%$ & $66.70 \%$ & $18.20 \%$ \\
\hline \multirow[b]{2}{*}{$\begin{array}{l}\text { Нypo } \\
\text { tension }\end{array}$} & Count & 27 & 2 & 0 & 29 \\
\hline & $\begin{array}{c}\% \\
\text { within } \\
\text { BMI }\end{array}$ & $13.00 \%$ & $2.70 \%$ & $0.00 \%$ & $9.40 \%$ \\
\hline \multirow[b]{2}{*}{ Total } & Count & 208 & 73 & 27 & 308 \\
\hline & $\begin{array}{c}\% \\
\text { within } \\
\text { BMI }\end{array}$ & $100.00 \%$ & $100.00 \%$ & $100.00 \%$ & $100.00 \%$ \\
\hline
\end{tabular}

Pearson Chi-Square Value $<.001$

The above Table 1 shows correlation of BMI with Blood Pressure. A highly statistical significant correlation $(\mathrm{p}<.001)$ is seen between BP and BMI where in a trend of increasing proportion of high BP is seen from normal BMI to overweight and obese; $66.7 \%$ of obese students reported to have high BP.

$42.5 \%$ overweight were with high BP and only $3.4 \%$ with normal BMI recorded high BP. The table also reflected that $18.2 \%$ of students across all BMI categories have high BP, while $72.4 \%$ were found to have normal BP and $9.4 \%$ were found to have lower than normal BP at the time of measurement of these parameters.

\section{DISCUSSION}

Overweight and obesity was recognised as an 'escalating epidemic' affecting both developed and developing countries. The WHO has declared obesity as a disease of pandemic significance. 11 The increasing prevalence of hypertension is attributed to population growth, ageing and behavioural risk factors such as unhealthy diet, harmful use of alcohol, lack of physical activity, excess weight and exposure to persistent stress. $^{8}$ The review paper has reported that although a decrease in salt intake during dieting may contribute to the blood pressure lowering effect of weight reduction, also other mechanisms such as reduction in plasma renin activity and a decrease in sympathetic tone may also be involved. A recent meta-analysis in Asia Pacific Cohort Studies collaboration demonstrated age dependent relationship between BMI and the incidence of Diabetes Mellitus through the entire Asia Pacific region. ${ }^{12}$ Adolescent obesity is on the rise and is associated with adverse ill effect. Excessive body weight including overweight and obesity together with hypertension represents major threats to civilization in the $21^{\text {st }}$ century. ${ }^{13} \mathrm{~A}$ significant correlation has been demonstrated between BMI and BP, suggesting that BMI contributed to the reported hypertension. Abnormal BMI is found to be associated with increased risk of CHD and Type 2 Diabetes Mellitus. ${ }^{14}$ Himes and Dietz reporting the committee recommendation stated that BMI for age be used to routinely screen for overweight in adolescents. ${ }^{15}$ WHO has defined obesity as disease in which fat has accumulated to an extent that health is adversely affected, links the condition to both excess fatness and risk. ${ }^{16}$ Obesity and overweight are leading risk factors for a number of chronic diseases and major risk contributor to preventable cause of death. Obesity is a leading determinant of hypertension, dyslipidaemia and diabetes mellitus. ${ }^{17}$

Students who were overweight exercise and decreased their weight by $2 \mathrm{~kg}$ showed a decrease in body age. This shows that the body age is correlated with body weight. Lesser the weight, lower the BMI, visceral fat and closer the body age with the person's actual age. The heart needs to work more if there is more fat tissue around the capillaries. The need to reduce fat in woman accumulated in the hips and males in abdomen, i.e. gynoid/android form of obesity is essential to give rest to the heart and promote longevity and fitness. By right eating, exercise and right thinking the students were counselled to follow health laws. Many studies have reported a significant relationship between hypertension and risk factors such as age, BMI, smoking and physical inactivity. ${ }^{18}$ These are also the main causes of increase in body age [biological age] based upon our fitness level. Regular activity is a key part of managing diabetes along with proper meal planning, taking medications as prescribed and stress management. When we are active our cells become more sensitive to insulin, so it can work more efficiently. Our cells also remove glucose from the blood using the mechanism totally separated from insulin during exercise. Therefore, physical activity has important health benefits for children and young adolescents and is also associated with more resistible biological cardiovascular disease risk factor profiles by lowering blood pressure, maintaining the lipoprotein levels and decreases the adiposity and thus enhancing their abilities to perform daily tasks. ${ }^{19}$ The benefits of regular physical activity also includes lowering of cholesterol level, burning of calories to maintain weight, strengthening the heart for proper blood circulation, muscles and bones, maintaining the flexibility of joints, improving the balance to prevent falls, reducing symptoms of depression and improving the quality of life.

\section{CONCLUSION AND SUMMARY}

In the present study, body weight, height and BP were measured in 308 students of first year medical, dental and nursing courses, out of which 131 (43\%) were males and 177 
(57\%) were females. Majority $218(70.8 \%)$ of students were in the age group of $18-20$ years, 70 students $(22.7 \%)$ were in the age group of 20-22 years and only small proportion were either younger than 18 years $(5.8 \%)$ or older than 22 years $(0.6 \%)$. In the present study, we also studied some behaviour and practices of students. It was encouraging to note that only a small proportion of subjects 21 (6.5\%) reported to consume any form of tobacco.

Alcohol consumption is showing an increasing trend in the society and young people have much larger exposure to it. Amongst those who were pursuing trained exercises (13.2\%), a larger proportion (27.6\%) was pursuing mild exercises and much smaller proportion (4.9\%) was actually doing severe intensity exercises. The present study also reported an association between BMI and respiratory rate as the increase in $\mathrm{RR}>20$ per minute were seen from normal BMI to obesity.

It was clear from present study that BMI is statistically correlated with BP and the findings of our study is also in conformity and agreement with many other studies including special surveys. Given this trend, it is important to undertake prevention and control programs to make young people aware of harmful effects of sedentary lifestyles, benefits and usefulness of maintaining a healthy BMI and to undertake measures of reducing weight and fat by regular exercise, proper dieting, risk factors such as smoking and alcohol intake for which young people need to be counselled for stopping.

By right eating, exercise and right thinking the students were counselled to follow health laws. Two words makes a person healthier: Eat less. There are lots of reasons for people to lose weight. To be healthier, To look better, To feel better, or To have more energy. No matter what the reason, successful weight loss and healthy weight management depend on sensible goals and expectations. The foundation of a successful weight loss program remains a combination of a healthy diet and exercise customised for you. Simply reducing food intake to lose weight can lead to a decline in muscle mass and bone density. So even though the weight goes down, resting metabolism is reduced making the body more prone to putting on fat. More skeletal muscle can prevent "rebound" weight gain. Exercising half hour daily for 5-7 times a week can help lose weight, improve fitness and mental alertness.

\section{REFERENCES}

1. Kearney PM, Whelton M, Reynolds K, et al. Worldwide prevalence of hypertension: a systematic review. Journal of Hypertension 2004;22(1):11-9.

2. Nanda AR. Addressing the reproductive health needs of adolescents in India: directions for programmes. Towards adulthood: exploring the sexual and reproductive health of adolescent in South Asia. WHO, 2003:43-4.

http://whqlibdoc.who.int/publications/2003/92415625 01.pdf

3. Nanaware NL, Gavkare AM, Surdi AD. Study of correlation of body mass index (BMI) with blood pressure in school going children and adolescents. International Journal of Recent Trends in Science And Technology 2011;1(1): 20-6.

4. Jousilahti P, Tuomilehto J, Vartiainen E, et al. Body weight, cardiovascular risk factors and coronary mortality: 15 year follow-up of middle-aged men and women in eastern Finland. Circulation 1996;93(7):1372-9.
5. Kasper DL, Braundwald E, Fauci AS, et al. Harrison's principles of internal medicine. $16^{\text {th }}$ ed. Vol. 1. United States of America. The McGraw Hill Companies 2005: 422-9.

6. National High Blood Pressure Education Program Working Group on High Blood Pressure in Children and Adolescents. The fourth report on the diagnosis, evaluation and treatment of high blood pressure in children and adolescents. Paediatrics 2004;114(2 Suppl $4^{\text {th }}$ Report):555-76.

7. Lurbe E, Cifkova R, Cruickshank JK, et al. Management of high blood pressure in children and adolescents: recommendations of the European society of hypertension. J Hypertension 2009;27(9):1719-42.

8. A global brief on hypertension: silent killer, global health crisis:WHO/DCO/WHD/2013;2:1-40.

http://www.who.int/cardiovascular_diseases/publicatio ns/global_brief_hypertension/en/

9. Kishan A. A cross-sectional study of anthropometric, blood pressure parameters and metabolic profile among medical students-gender difference determines cardiovascular risk. International Journal of Pharmaceutical, Biological and Chemical Sciences 2016;5(2):1-10.

10. Collins R, Peto R, McMahon S, et al. Blood pressure, stroke, and coronary heart disease. Part II, effects of short term reduction in blood pressure: overview of randomized drug trials in an epidemiological context. Lancet 1990;335(8693):827-38.

11. World Health Organization: Obesity epidemic puts millions at risk from related diseases. June 12 1997. URL: http://www.who.int/infprp1997/ en/pr97-46. html

12. Asia Pacific Cohort Studies Collaboration. Ni Mhurchu C, Parag V, Nakamura M, et al. Body mass index and risk of diabetes mellitus in the Asia-Pacific region. Asia Pac J Clin Nutr 2006;15(2):127-33.

13. Graf C, Jouck S, Koch B, et al. Obesity, blood pressure and health-related behavior among German children and adolescents. Physical Education and Sport 2008;52:5761.

14. Gillman M, Cook N, Rosner B. Prediction of adult blood pressure from childhood values (Abstract). Am J Epidemiol 1999;134:730.

15. Himes JH, Deitz WH. Guidelines for overweight in adolescent preventive services: recommendations from an expert committee. The expert committee on clinical guidelines for overweight in adolescent preventive services. American Journal of Clinical Nutrition 1994;59(2):307-16.

16. Neovius M, Linne Y, Rossner S. BMI, waist circumference and waist hip ratio as diagnostic test for fatness in adolescents. Int J Obes 2005;29(2):163-9.

17. Njelekela MA, Mpembeni R, Muhihi A, et al. Gender related differences in the prevalence of cardiovascular disease risk factors and their correlates in urban Tanzania. BMC Cardiovasc Disord 2009;9:30.

18. Hennessy E, Hughes SO, Goldberg JP, et al. Parent child interactions and objectively measured child physical activity, a cross-sectional study. International Journal of Behavioral Nutrition and Physical Activity 2010;7:71.

19. Dubbert PM, Carithers T, Sumner AE, et al. Obesity, physical inactivity and risk for cardiovascular disease. American Journal of the Medical Sciences 2002;324 (3):116-26. 